occasion divided into two parts-viz., first about two ounces, being that passed at the commencement of micturition, and secondly the remainder. On every occasion that the urine was examined for six consecutive days it appeared to the naked eye to be normal; the only appreciable difference between the two portions was that the second part deposited a much larger proportion of mucus than the first. Microscopically, a fow stray red corpuscles were seen, and these occurred far more frequently in the second part of the urine. On the first occasion, finding a small shred which was passed at the end of micturition, 1 placed it on a slide, and found that it was a small slough in which were embedded two ova of the bilharzia, and on every subsequent occasion I was able to find at least one or two ova, though the urine remained quite clear and pale. My evidence was given accordingly, and on this and other evidence the prisoner was convicted and dealt with.

Another observation of mine comes under this heading. At a necropsy performed for a coroner's jury, I reserved portions of the viscera for microscopic examination. The subject was a native; the case one of general disseminated tuberculosis; and it is possible that any appearance due to the presence of the bilharzia was masked by the tubercular ulceration of the mucous surfaces. On examining some of the sections of lung, I found groups of two or three ova embedded in the interstitial fibrous tissue. These ova varied in length from 0.95 to $0.12 \mathrm{~mm}$; and though not furnished with any very distinct spine, they corresponded exactly with those figured by Kartulis ${ }^{3}$ as the ova of bilharzia occurring in the liver and kidney; and if they were really such, my observation is not unique, for BirchHirschfeld has seen the ova in the lung in sections prepared by Dr. Schieff Bey of Alexandria.* As, however, 1 have found them in the lung only, I have provisionally labeled the slides "Bilharzia (?)" for it is possible that future observations may show that the Distoma Ringeri also occurs on the Gold Coast.

Accra, Gold Coast.

\section{CASE OF INVERSION OF THE UTERUS, WTH COMPLETE PROLAPSE.}

BY F. S. BARBen, L.R.C.P. LoND., M.R.C.S.

MRs. L-, multipara came under my care during the third month of pregnancy, complaining of inability to pass urine, together with a swelling at the vulva. On examination, I found the uterus large, prolapsed, and wedged at the orifice of the vagina. The prolapse was rectified, and the bladder relieved by the catheter. Afterwards I introduced an ordinary Hodge's pessary; this gave great relief, and prevented any further recurrence. She wore the pessary for a month or more, and was then able to dispense with its support. In June labour commenced, and was attended by my assistant, who found on his arrival that the passages were relaxed and dilated, together with a normal presentation. After a few powerful pains the birth of the foetus was accomplished, but was immediately followed by a prolonged and very severe pain and bearing-down, which caused the whole uterus to become inverted and extruded through the vulva, with the placenta still adherent to the fundus. The patient became faint, the pulse almost imperceptible, and the body covered with a clammy sweat. I was immediately sent for, and arrived within a few minutes. Needless to say I was somewhat alarmed at the state of affairs, and proceeded at once to diagnose the cause. On placing my hand on the abdomen, I could detect no contracted uterus; but on examining the mass (which was literally in the bed), I made out an inverted uterus with the placenta still attached. I tried to reduce it through the vulva as it was, and partly succeeded, but was unable to reduce the inversion without first detaching the placenta; this $I$ did, and, although the hæmorrhage was very profuse, I was able to replace it in a few seconds, but not without having to try twice. The general condition of the patient was most serious. She was insensible, pulseless, and the extremities cold. After lowering the head and applying heat to the extremities, she was able to drink some brandy-and-water, to which I added liq. ergotæ (one drachm). By degrees she gradually recovered consciousness, and was able to recognise friends. During this time I had kept my hand upon the uterus, and was pleased to feel it contract under my pressure; the hæmorrhage ceased, and the present danger seemed, as it proved to be, past. The after attendance on the case varied but lictlo from ordinary cases, save that I was more anxious, and consequently more attentive. The uterus as well as vagina were syringed with weak Condy's fluid, and opium and quinine prescribed for ten days.

Remarks. - In the treatment of this case I had occasion to resort to two methods of reduction-viz., (1) by pressure of the closed hand direct to the fundus; and (2) by the pressure applied by the fingers at the sides of the massthat is, on the lateral portion (in both cases I had my hand externally to support the abdominal wall); and it was with the latter method that I was successful. The hæmorrhage was hardly as profuse as a number of gaping sinuses would lead one to fear, but I should imagine a condition of semi-strangulation existed.

Bradford.

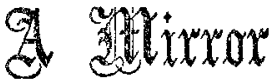

\section{HOSPITAL PRACTICE, BRITISH AND FOREIGN.}

Ninla autem est alia pro certo noscendi via, nisi quamplurimas et morcorum et dissectionum historias, tum aliorum tum proprias collectas habere, et inter se comparare.-MoRgagnI De. Sed. et Caus. Morb.
lib. iv. Procemium.

\section{PADDINGTON INFIRMARY.}

ABSCESS OF LIVER; OPERATION; RECOVERY; REMARKS.

(Under the care of Mr. H. ELwIN HaRRIs, B.A., essistant medical superintendent.)

A LARGE single abscess of the liver is so uncommon when not of the variety known as "tropical" that this case is of much interest. The remarks appended to the record are important; it is possible, however, that it may have been of pyæmic origin from the acuteness of its onset and the presence of a possible source in the sore on the leg, but the hepatic abscesses in that disease are usually multiple, and the satisfactory progress after operation negatives this view.

A. G-aged forty-nine, unmarried, a cook, was admitted on Feb. 5 ch, 1887, suffering from a red, tender, fluctuating swelling on the inner aspect of the right leg, about three inches above the malleolus; she had had a slight injury to the leg before admission, but had noticed the swelling previously to that. An incision was made and a large slough discovered at the base, the edges of the incision being much undermined; the whole appearance was very suggestive of a gumma. Some sloughing of the tissues followed, but it began steadily to heal under ten-grain doses of iodide of potassium administered three times a day over a period of a month.

On April 8th, about 5 P.M., the patient complained of feeling very cold, and shivered. The temperature was found to be $104^{\circ}$ and the pulse 120 . This was followed by profuse perspiration, but she complained of no pain. The ulcer had now nearly healed, and there was nothing in its appearance which would suggest any explanation of the symptoms. On examination, there was tenderness on pressure over the hepatic region, but there was no enlargement either of the liver or spleen. Fifteen grains of sulphate of quinine were administered internally, and poultices of linseed and opium applied to the hepatic region.

April 13th.-Increased tenderness on pressure over the liver, the dulness of which extended to four inches below the level of the costal arch in the nipple line. No jaundice. The temperature had assumed a hectic type, rising to about $102^{\circ}$ in the evening and falling to normal in the morning. Twelve leeches were applied over the hepatic region, and a pill of quinine and opium given every four hours. The ulcer of the leg had now quite healed.

17th.-CEdema and redness of the abdominal walls were present over the enlarged liver, and the aspirator inserted at this point drew off twelve ounces of thick fetid pus. The patient was much collapsed after the aspiration. Temperature $96^{\circ}$; skin cold and clammy. She complained of no pain, however, excepting on movement or pressure.

21st. - The patient complained of pain in the abdomen 
during the night; profuse sweats; cedema of abdominal walls; tympanites; some ascites.

24 th.-The patient was placed under an anæsthetic, and an ohlique incision made through the abdominal walls, about three inches in length, parallel to, and an inch and \& half below, the cartilages of the lower ribs, and dividing the rectus abdominis. The peritoneum was firmly adherent. A trocar was then inserted, and was followed by an escape of pus. A grosved director having been passed in, the abscess cavity was laid freely open. Sixteen ounces ot pus, thick, grumous, but not offensive, poured out. The cavity was very irregular in outline, though its walls were smooth; in size it was about that of a cricket ball. Two drainage tubes, fastened side by side, were fixed by means of a silk suture, and the wound dressed antiseptically.

25th. - The patient passed a good night, but had some pain. Temperature $97.8^{\circ}$ in the morning; pulse $102^{\circ}$. She had romited twice during the night. Legs very oedematous. The wound was dressed, pus pouring out on removal of previous dressing. Urine: sp. gr. 1022; acid, with the faintest trace of albumen.

27th.-Wound dressed; discharge still. profuse; wound looking healthy; abdomen tympanitic; legs still odematous. Temperature normal; pulse 96 . Complained of a little pain in the right side.

May 5th.-The general condition had improved; there was still a copious discharge of pus, but the cavity and orifice of the wound had contracted very much. The tympanitis had subsided and the cedema of legs was much less. The patient slept and took nourishment well. Temperature normal; pulse 96. From this date the putient gradually improved and made a, perfoct recovery.

Remarks by Mr. HanRIs.-This case of a large solitary abscess of the liver is interesting, more especially because of the obscurity of its origin. The idea of a "tropical" abscess may be at once dismissed, the only foreign part in which the patient had resided being Boulogne, and she had never had dysentery or any disease of the rectum. A question which perhaps is worthy of consideration is that of gummata, undergoing softening, becoming fused together, and thus forming one large abscess. It is true the patient had had what to all appearances was a gumma on the lower extremity, but this had healed under treatment, and it seems highly improbable that whilst the good effects of potassium iodide were manifesting themselves in one part of the body gummata should form and eventually break down in another. It is not likely that any local cause, such as an impacted gall-stone, could give rise to such a result without pain and without jaundice; it is far more probable that the abscess was due to the suppuration of some pre-existing though undiscovered cyst, such as a hydatid, although no cysts were visible in the fluid which escaped, and it is to be regretted that the fluid was not examined microscopically. With reference to the treatment, it would probably have been better not to have allowed so long an interval to elapse between the establishment of the presence of pus by the aspirator and the incision into the abscess cavity. Against any advantage gained by a more perfect consolidation of the layers of the peritoneum must be noted the further destruction of tissue and the greater accumulation of pus which took place during that time, and it seems probable that had the odema and redness of the abdominal walls been taken as an indication that the peritoneum was adherent her recovery might have been accelerated. The cdema of the legs was probnbly due to pressure on the inferior vena cava by the inflamed liver tissue.

\section{WINDSOR STATION HOSPITAL.}

FRACTURE OF THE FIFTH CERVICAL VERTEBRA, WITH COMPRESSION OF THE SPINAT CORD; DURATION OF LTFE TEN MONTHS.

(Cnder the care of Surgeon-Major MYens.)

PRIVATE S-, Grenadier Guards, a very strong man, aged twenty-three, weight 14 st., was admitted on July 3rd, 1886. He stated that whilst bathing in the Thames, near Windsor, he dived head foremost into shallow water (two feet), and was taken out almost immediately by some comrades, who noticed that his legs were completely paralysed, and he was at once conveyed to the hospital. When seen shortly afterwards, he was lying on his back, perfectly conscious, but deroid of sensation and motion in the lower part of the trunk and legs. Slight sensation was present to about the lower angle of the scapulas, and there was some power of movement in both arms at the shoulder; respiration was entirely diaphragmatic; pulse slow and strong; the patient complained of no pain excepting at the back of the neck in the region of the fifth and sixth cervical vertebræ, and chiefiy on the left side. He stated that while lying under water he knew he was quite paralysed, but held his breath, hoping that assistance might be sent him. Careful notes of the case have been taken by Surgeons Alexander, Sheldrake, and Carte, of the Brigade of Guards, but as its great interest rests on the unusual prolongation of life, a tew comments only are needed.

Some days after admission the arms became motionless, excepting a slight power to raise the elbow from the side, and remained flexed. The sensation roturned in the right arm, but it soon became apparent in the left arm as low as the elbow, and extending over the anterior surface of the radial half of the forearm, and at a later period in the tips of the thumb and first and second fingers. Over and above the shoulders there was marked hyperæsthesia. For many weeks bedsores were well kept in check, though continually threatening, but in course of time they formed in numerous places, especially along the under surface of the right leg, and even on the toes, where no pressure occurred. At a later stage the integument of the back became completely undermined and converted into a large sac, containing very offensive pus. This sac, by irrigation twice daily with disinfectants through the sacral bedsore, completely disappeared; and a short time prior to death the bedsores of the right leg had healed, and others over the scapulæ, elbows, and hips had nearly done so, and even the deep sacral bedsore had greatly contracted. Cystitis sot in at an early stage, hastened probably by an acute attark of gonorrhoea, from which the patient was suffering on admission. This was completely arrested for a time by frequent irrigations with different disinfectants. Two months after admission the patient stated he could feel the flow of water from the irrigator into the bladder, and this regained some power, the urine being occasionally expelled with force, though unconsciously to the man. After some months slight reflex action of the leg muscles could be obtained by the galvanic battery and by tickling the soles of the feet, and tended to increase to the last. Latterly he began to raise both elbows to the level of his head, and flex the left arm sufficiently to enable him to touch his face with his fingers, but he could not bring the arms back to his side. Rotation of the head became quite free and painless, and considerable pressure could be borne over the seat of fracture without causing discomfort. The temperature rose irregularly till the evening of Aug. 16th, when it reached $1032^{\circ}$; after that date it gradually became normal or subnormal, and, excepting occasional short and sudden rises, remained so until the last week. The action of the bowels from first to last remained involuntary. About the middle of April, 1887, his appetite, which had been surprisingly good, began to fail, the urine became fetid, vomiting set in, the bedsores began rapidly to reappear, and on April 28th urine ceased to enter the bladder. Vomiting then became incessant, and on May 2nd the patient died.

At the post-mortem examination the cervical vertebra were removed. The kidneys were completely disorganised, the right one being almost entirely converted into one fetid abscess. The ureters were much dilated and thickened, and deeply stained. The bladder was also much hypertrophied and stained, and contained only a little fetid pus. There was nothing special to remark about the thoracic organg. The brain was not examined.

The following is a report of a sectional examination of the cervical vertebræ made by Dr. Silcock:-- "The body of the fifth cervical vertebra has been crushed and somewhat, displaced backwards, giving rise to a projection in the spinal canal. Opposite this projection the spinal cord is almost completely disorganised, evidently by the pressure exercised upon it."

\section{GLASGOW MATERNITY HOSPITAL.}

A CASE OF HEMTPLEGIA DURING THE PUERPERIUM.

(Under the care of Dr. SAMUEL StoAN.)

THE following notes were communicated by Ernest, Roberton, M.B. Edin., in-door house surgeon of the hospital, in a paper read before the Glasgow Obstetrical and Gynæcological Society.

Mrs. D- - aged thirty, was admitted on May 22nd, 1887. 